\title{
Restraining FOXO3-dependent transcriptional BMF activation underpins tumour growth and metastasis of E-cadherin-negative breast cancer
}

\author{
M Hornsveld ${ }^{1,3}$, M Tenhagen ${ }^{2,3}$, RA van de Ven ${ }^{2}$, AMM Smits ${ }^{1}$, MH van Triest $^{1}$, M van Amersfoort ${ }^{2}$, DEA Kloet ${ }^{1}$, TB Dansen ${ }^{1}$, \\ BM Burgering ${ }^{1}$ and PWB Derksen ${ }^{*, 2}$
}

Loss of cellular adhesion leads to the progression of breast cancer through acquisition of anchorage independence, also known as resistance to anoikis. Although inactivation of E-cadherin is essential for acquisition of anoikis resistance, it has remained unclear how metastatic breast cancer cells counterbalance the induction of apoptosis without E-cadherin-dependent cellular adhesion. We report here that E-cadherin inactivation in breast cancer cells induces PI3K/AKT-dependent FOXO3 inhibition and identify $\mathrm{FOXO} 3$ as a novel and direct transcriptional activator of the pro-apoptotic protein BMF. As a result, E-cadherin-negative breast fail to upregulate BMF upon transfer to anchorage independence, leading to anoikis resistance. Conversely, expression of BMF in E-cadherin-negative metastatic breast cancer cells is sufficient to inhibit tumour growth and dissemination in mice. In conclusion, we have identified repression of BMF as a major cue that underpins anoikis resistance and tumour dissemination in E-cadherin-deficient metastatic breast cancer.

Cell Death and Differentiation (2016) 23, 1483-1492; doi:10.1038/cdd.2016.33; published online 1 April 2016

Development and homeostasis of glandular structures such as the mammary gland depend on spatiotemporal induction of apoptosis upon loss of cell-cell and cell-matrix attachment, a process known as anoikis. ${ }^{1,2}$ Proper anoikis regulation ensures the formation of hollow lumen within a glandular epithelium structure by induction of apoptosis in selective non-polarised luminal epithelial cells that line the ductal structures. ${ }^{3,4}$ In the mammary gland, the pro-apoptotic proteins BIM and BMF induce apoptosis upon cell detachment and as such contribute to the formation of mammary ductal lumen.,

Anoikis is regulated by an intricate regulation of the balance between pro-apoptotic and anti-apoptotic proteins. ${ }^{7}$ Antiapoptotic BCL-2 family proteins (BCL-2, BCL-xL and MCL1) compete with the pro-apoptotic molecules (BIM, PUMA, NOXA, BID, BAD or BMF) for binding to BAK and BAX to prevent mitochondrial membrane permeabilisation and subsequent apoptosis. Expression of pro-apoptotic proteins can be induced by a variety of stresses, including DNA damage, nutrient deprivation, heat and hypoxia. ${ }^{8}$ BMF appears to specifically function to induce anoikis in epithelial cells. ${ }^{5,9}$ It is, however, still controversial whether activation of factors such as BMF is induced through transcriptional activation or by posttranslational events in the cytosol. ${ }^{10}$

Correct execution of apoptosis in luminal mammary cells is deregulated during the early stages of breast cancer, such as atypical hyperplasia and ductal carcinoma in situ, resulting in filling of the mammary duct with anoikis-resistant cells. ${ }^{11}$
Several studies have shown that activation of oncogenic growth factor receptor (GFR) signalling can induce aberrant filling of the luminal space.,5,12 Similar effects have been observed upon inhibition of pro-apoptotic players such as BIM, BMF and $\mathrm{p} 53,{ }^{5,6,13}$ indicating that either GFR activation and/or the inhibition of distal pro-apoptotic effectors underlie anchorage independence of breast cancer cells. Indeed, mutations in the PI3K and p53 pathway are among the most observed mutations in epithelial cancers, including breast cancer. ${ }^{14}$ Moreover, hyperactivation of $\mathrm{PI} 3 \mathrm{~K}$ and its downstream effector AKT/PKB can lead to repression of apoptosis through phosphorylation-dependent inactivation of pro-apoptotic proteins, such as BAD. $5,15,16$

Enhanced growth factor signalling can also be induced through downregulation of the epithelial adherens junction (AJ). ${ }^{17,18}$ E-cadherin is the core component of the $\mathrm{AJ}$ and a master regulator of epithelial integrity, linking the cell membrane to the cytoskeleton. ${ }^{19}$ Although loss of E-cadherin in the mammary gland is not tolerated, ${ }^{20-22}$ mammary-specific E-cadherin inactivation following loss of p53 in mice leads to the acquisition of anoikis resistance of tumour cells and subsequent dissemination, demonstrating E-cadherin loss as a prerequisite for metastatic disease progression. ${ }^{23}$

Despite its repression by growth factor signals, the apoptotic machinery is functionally intact in cancer cells. Targeting the apoptotic machinery has become increasingly interesting in cancer therapy, as intervention strategies using novel

\footnotetext{
${ }^{1}$ Department of Molecular Cancer Research, University Medical Center Utrecht, Utrecht, The Netherlands and ${ }^{2}$ Department of Pathology, University Medical Center Utrecht, Utrecht, The Netherlands

*Corresponding author: PWB Derksen, Department of Pathology, University Medical Center Utrecht, H04.312, Heidelberglaan 100, Utrecht, CX 3584, The Netherlands. Tel: +31 88 7568086; E-mail: pderksen@ umcutrecht.nl

${ }^{3}$ These authors contributed equally to this work.

Abbreviations: GFR, growth factor receptor; AJ, adherens junction; Ad, adherent; Sus, suspension; FACS, fluorescent-activated cell sorting; ChIP, chromatin immunoprecipitation; iBMF, inducible BMF; iFOXO, inducible FOXO3; Dox, doxycycline

Received 10.8.15; revised 24.2.16; accepted 01.3.16; Edited by C Borner; published online 01.4.2016
} 
$\mathrm{BH}-3-o n l y$ protein mimetic compounds in combination with dual specificity inhibitors of PI3K and mTOR have shown promising results. ${ }^{24,25}$ Here we have identified BMF as a direct transcriptional target of $\mathrm{FOXO} 3$ in breast cancer cells. Our data show that FOXO-dependent BMF expression is repressed in E-cadherin-negative and metastatic breast cancer cells and that expression of BMF is sufficient to inhibit tumour growth and dissemination in mice. We have thereby linked loss of E-cadherin to a cell intrinsic inhibition of BMF-dependent anoikis, a crucial step in malignant tumour progression.

\section{Results}

Anoikis-resistant breast cancer cells restrain the expression of BMF. To identify the proteins that control anchorage independence of metastatic breast cancer cells, we cultured E-cadherin-expressing anchorage-dependent and anoikisresistant E-cadherin-negative breast cancer cells from mouse and human origin in suspension (Sus). Under these conditions, the non-metastatic mouse mammary carcinoma cell line $\operatorname{Trp5} 53^{\Delta / \Delta}-4$ and human MCF7 underwent anoikis as previously demonstrated. ${ }^{20,26}$ In contrast, mouse and human E-cadherin-negative mILC1 and MDA-MB-231 cells were anoikis resistant (Figures 1a and $b$ ).

To determine which of the key anti-apoptotic and proapoptotic molecules were induced during anoikis, we assayed the protein and mRNA expression levels of the anti-apoptotic family members $B C L 2, B C L-X L$ and MCL1 and the proapoptotic NOXA, PUMA, BIM, BID and BMF. We observed that all cell lines upregulated BCL2 protein levels and showed increased BID cleavage under anchorage-independent conditions regardless of E-cadherin status. For NOXA and PUMA, no changes were detected in protein levels (Supplementary Figure S1A). In line with previous findings, ${ }^{5,6,27}$ we detected a clear induction of BIM and BMF in the anoikis-sensitive $\operatorname{Trp53}^{\Delta / \Delta}-4$ and MCF7 (Figures 1c and d, Supplementary Figures S1B and C). In contrast, the metastatic cell lines mILC1 and MDA-MB-231 did not show a comparable upregulation of either BIM or BMF (Figures 1c and d, Supplementary Figures S1B and C). Subsequent quantitative PCR experiments demonstrated that the only pro-apoptotic gene that was transcriptionally upregulated in both mouse and human E-cadherin-expressing anchorage-independent cells was BMF (Figures $1 \mathrm{e}$ and $\mathrm{f}$ and Supplementary Figures S2A and $B$ ). We observed that, although $E$-cadherin-negative cells induced BMF under anchorage-independent conditions, the expression levels were 3-10-fold lower relative to $\operatorname{Trp5} 53^{\Delta / \Delta}-4$ and MCF7. These data demonstrate that anchorageindependent E-cadherin-negative cells restrain transcriptional upregulation of $B M F$, a key inducer of anoikis.

Despite the fact that BMF is the major pro-apoptotic factor that showed uniform transcriptional upregulation in suspension settings, at the protein level both BMF and BIM are increased (Figures $1 \mathrm{c}$ and $\mathrm{d}$ and Supplementary Figures S1B and C). To determine whether these two $\mathrm{BH} 3-$ only factors are specifically required to induce anoikis, we performed loss-of-function studies and assessed the effect of BMF and/or BIM loss on anoikis resistance of mouse and human E-cadherin-positive cells. Using two independent targeting sequences, we induced knockdown and observed that loss of either BMF or BIM led to a significant increase in anoikis resistance of $\operatorname{Trp}_{53}{ }^{\Delta / \Delta}$ and MCF7 cells (Figures $2 a-f$ ). Concomitant knockdown of BMF and BIM also resulted in a significant increase in anoikis resistance when compared with controls (Figures 2a-f). Overall, our data does not indicate that dual inhibition of BMF and BIM has an additive effect when compared with the single BMF knockdown experiments (Figures $2 a$ and b). In short, our data demonstrate that BMF and BIM both contribute to the induction of anoikis in E-cadherin-positive breast cancer cells. Further, our data indicate that BMF and BIM are nonredundant and have overlapping functions in the regulation of anoikis of E-cadherin-expressing cells. Overall, we show that BIM and BMF expression is increased upon transfer to anchorage-independent conditions to induce anoikis. However, our data indicate that, in contrast to BIM, the upregulation of BMF under these conditions is transcriptionally regulated.

Loss of E-cadherin results in anoikis resistance and restricts BMF expression. To determine whether E-cadherin loss is causal to the repression of BMF expression in breast cancer, we generated E-cadherin knockout cell lines using the CRISPR/Cas9 system. Guide RNAs targeting the E-cadherin locus were expressed in $\operatorname{Trp}_{53}{ }^{\Delta / \Delta}$ and MCF7 cells, which were subsequently fluorescent-activated cell sorted (FACS) based on E-cadherin expression, resulting in E-cadherin-negative cell lines. In contrast to control cells, the E-cadherin knockout cell lines failed to establish E-cadherinbased cell-cell junctions and consequently grew dispersed as solitary cells (Figure 3a). As expected, we observed that E-cadherin loss in mouse and human cells resulted in the acquisition of anoikis resistance (Figure 3b). Importantly, we noted a significant reduction of BMF expression in E-cadherin knockout cell lines relative to control cells upon transfer to anchorage independence (Figures $3 c$ and $d$ ). These results confirm that loss of E-cadherin is causal to the acquisition of anoikis resistance and show that loss of E-cadherin leads to transcriptional repression of BMF expression upon loss of cell-matrix attachment.

BMF expression is inhibited by growth factor signallingdependent repression of FOXO3. Because BMF was transcriptionally regulated upon transfer to anchorage independence, we hypothesised that either direct transcription repression or inhibition of a transcription factor could underlie the differential BMF expression in anoikis-resistant breast cancer cells. We therefore analysed the human genomic $B M F$ promoter region and identified two FOXO consensusbinding sites (TTGTTTA). FOXOs are directly regulated and suppressed by canonical PI3K/AKT signalling and known transcription factors for the pro-apoptotic genes BIM, NOXA and PUMA. ${ }^{28}$

To assess whether BMF is a direct FOXO target, we performed a chromatin immunoprecipitation (ChIP) with the most ubiquitously expressed FOXO transcription factor, FOXO3. To this end, we stably introduced a doxycycline (Dox)-inducible FOXO3 (iFOXO) construct in MCF7 cells and performed ChIP in the presence of the allosteric inhibitor VIII (AKTi) to prevent upstream inhibition of FOXO3 by AKT. In line with the predicted binding sites, we noticed binding of $\mathrm{FOXO} 3$ 
a

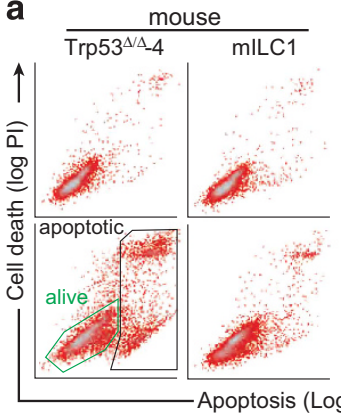

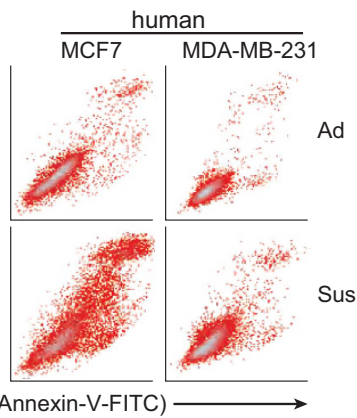

b

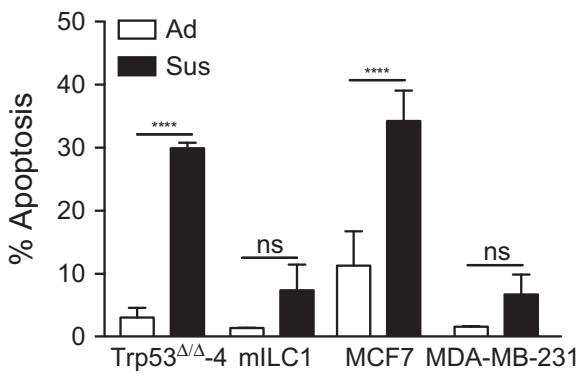

C

$\underline{\operatorname{Trp}^{5} 3^{\Delta / \Delta}-4} \quad \underline{\text { mILC1 }}$

Ad Sus Ad Sus

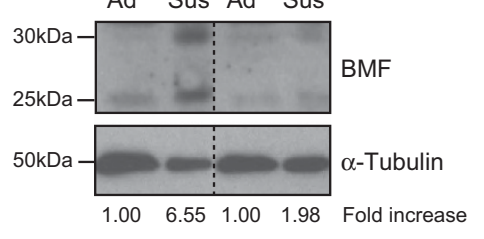

d

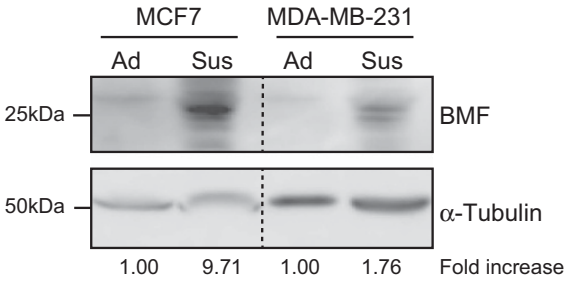

e
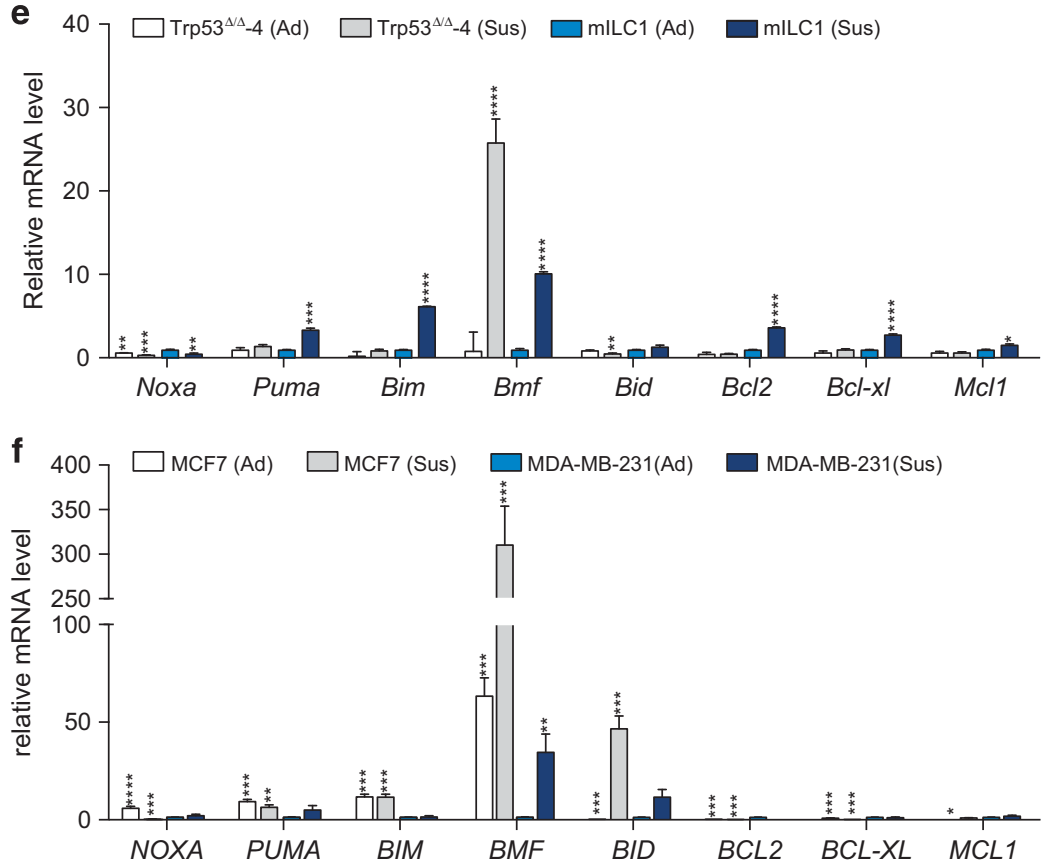

Figure 1 Anchorage-independent E-cadherin-negative breast cancer cells restrain BMF expression. (a) Anoikis resistance in the E-cadherin-negative breast cancer cell lines mILC1 and MDA-MB-231. Shown are flow cytometric analyses of apoptosis and cell death using Annexin-V-FITC (fluorescein isothiocyanate) and propidium iodide after 24-h adherent (Ad) and suspension (Sus) conditions. Note the robust induction of anoikis in the E-cadherin-expressing cells $\operatorname{Trp5} 3^{\Delta / \Delta}-4$ and MCF7. (b) Quantification of anoikis induction measured by flow cytometry in panel (a). Data represent mean \pm S.D., $n=3, t$-test ${ }^{*} P<0.05,{ }^{\star \star} P<0.005,{ }^{* \star} P<0.0005$. (c and d) Western blotting analysis of BMF and $\alpha$-Tubulin protein levels in Trp53 $3^{\Delta / \Delta}-4$ and mILC1. Blots are cropped in correspondence to the black box (c) and MCF7 and MDA-MB-231 cells grown under Ad and Sus conditions. Blots are cropped corresponding to the black box. (e and f) Quantitative PCR analysis of Noxa, Puma, Bim, Bmf, Bid, Bcl2, Bcl-xl and Mcl1 mRNA expression in Trp53 $3^{\Delta / \Delta}-4$ and mILC1 and MCF7 and MDA-MB-231 cultured in Ad and Sus culture. Data are relative to mRNA levels in Ad mILC1 cells (e) or MDA-MB-231 cells (f). Data represent the mean \pm S.D., $n=3$, $t$-test ${ }^{*} P<0.05,{ }^{* \star} P<0.005,{ }^{* * *} P<0.0005$

to both consensus sites in the BMF promoter (Figure 4a). We confirmed these results by analysing induction of $B M F$ upon expression of a dominant active form of FOXO3 (FOXO3.A3) ${ }^{29}$ and showing that administration of Dox indeed resulted in a robust induction of $B M F \mathrm{mRNA}$ and protein levels upon FOXO3 activation (Figures $4 \mathrm{c}$ and d, Supplementary Figures S3A-C and S4A and B).
To determine whether FOXO3 activation was sufficient to induce anoikis in E-cadherin-negative cells, we cultured mILC1-iFOXO3.A3 and MDA-MB-231-iFOXO3.A3 in suspension and assayed anchorage-independent survival. Addition of Dox triggered anoikis in mILC1 (Figure 4b), confirming that FOXO activation is indeed sufficient to prevent anchorage independence in E-cadherin-negative breast cancer cells. 

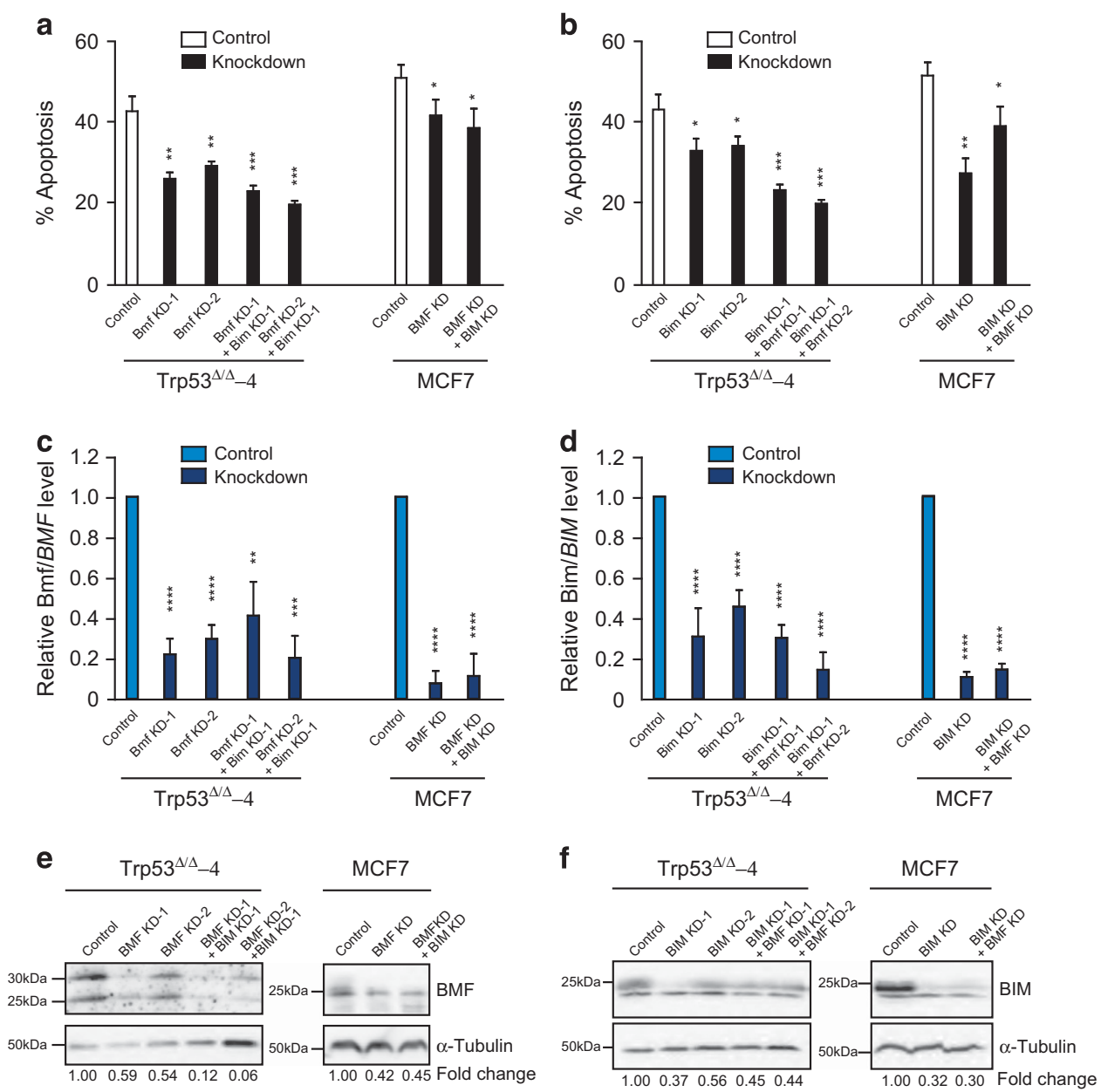

Figure 2 Loss of BMF or BIM increases anoikis resistance of E-cadherin-expressing breast cancer cells. (a and $\mathbf{b})$ Knockdown of BMF and BIM reduces apoptosis of $\operatorname{Trp}_{5} 3^{\Delta / \Delta}$ and MCF7 cells cultured in Sus. Flow cytometric quantifications of apoptosis using Annexin-V-FITC (fluorescein isothiocyanate) and propidium iodide after $24 \mathrm{~h}$ in Sus culture. (c and d) Quantitative PCR analysis of BMF and BIM mRNA knockdown efficiency. Data represent the mean \pm S.D., $n=3, t$-test ${ }^{*} P<0.05,{ }^{* \star} P<0.005$, ${ }^{* * *} P<0.0005,{ }^{* * * *} P<0.0005$. (e and f) Western blotting analysis of BMF and BIM protein levels shows successful BMF and BIM knockdown in Trp53 ${ }^{\Delta / \Delta}$ and MCF7 cells cultured in Sus. Blots are cropped corresponding to the black box

Although MDA-MB-231-iFOXO3.A3 cells showed a modest increase in BMF expression upon expression of $\mathrm{FOXO} 3$ (Supplementary Figure S4B), this did not lead to anoikis, which indicates that the induced BMF levels were insufficient to cause apoptosis in these anchorage-independent breast cancer cells.

Activation of the PI3K/AKT pathway by GFR signalling and ectopic expression of either oncogenic $\mathrm{PI} 3 \mathrm{~K}^{\mathrm{E} 545 \mathrm{~K}}$ or myristoylated AKT1 results in repression of anoikis in mammary epithelial cells. ${ }^{5}$ Interestingly, we have previously shown that inactivation of E-cadherin function in cancer cells results in hypersensitisation of GFR signalling without activating mutations. ${ }^{18}$ To confirm that active PI3K/AKT signalling, which is an established upstream inhibitor of FOXO, controls anoikis resistance, we cultured mILC1 cells and the MCF7- $\triangle \mathrm{CDH} 1$ cells in suspension and inhibited AKT activation using AKTi, and observed that AKTi resulted in a twofold increase in anoikis (Figures $5 \mathrm{a}$ and $\mathrm{b}$ ). More important, we could show that AKT inhibition resulted in a 2-3-fold upregulation of $B M F$ mRNA and protein expression in anchorage-independent cells (Figures $5 c-e$ ).
In conclusion, our data show that E-cadherin-negative metastatic breast cancer cells restrain anoikis through PI3K/ AKT signalling, a cue that subsequently inhibits $\mathrm{FOXO}-$ dependent transcriptional activation of its pro-apoptotic target $B M F$.

Upregulation of BMF expression restrains anchorageindependent tumour growth and metastasis of E-cadherin-negative mammary cancer in mice. Because BMF was the major pro-apoptotic factor upregulated in anoikis-sensitive breast cancer cell lines, we determined whether induction of BMF expression was sufficient to induce anoikis in E-cadherin-negative breast cancer cells. To this end, we stably introduced a Dox-inducible BMF cDNA expression system (BBMF) in mILC1 and MDA-MB-231 cells (Figure $6 \mathrm{a}$ ) and assayed anoikis resistance. Expression of BMF was indeed sufficient to cause a marked increase in apoptosis in both cell types (Figures $6 \mathrm{~b}$ and $\mathrm{c}$ ). Moreover, treating mILC1 and MDA-MB-231 cells with increasing concentrations of the BH3-mimetic drug ABT-199 induced a dose-dependent execution of apoptosis (Figure 6d), 
a

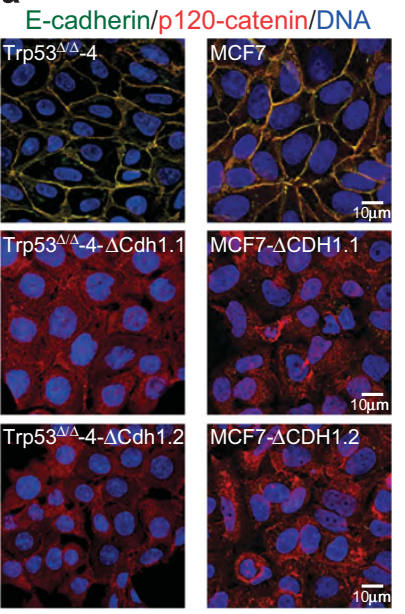

b

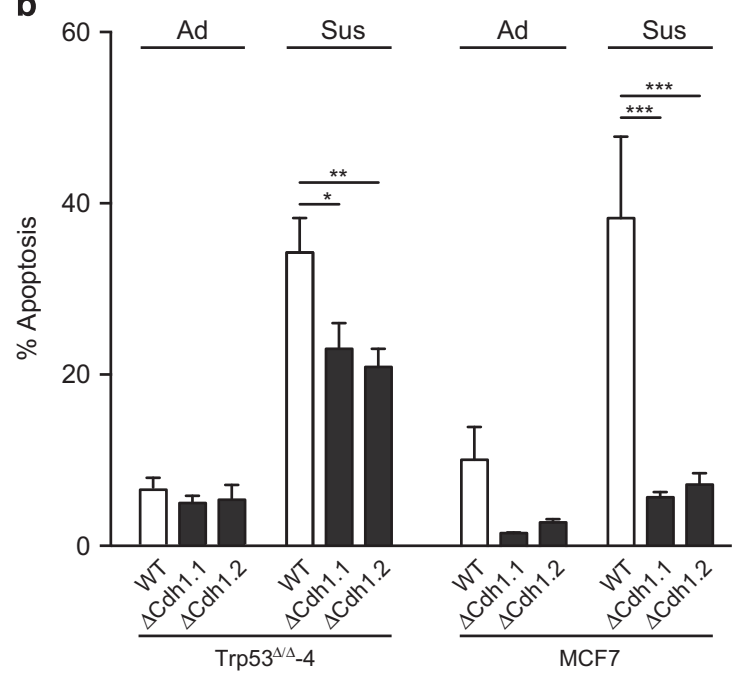

C

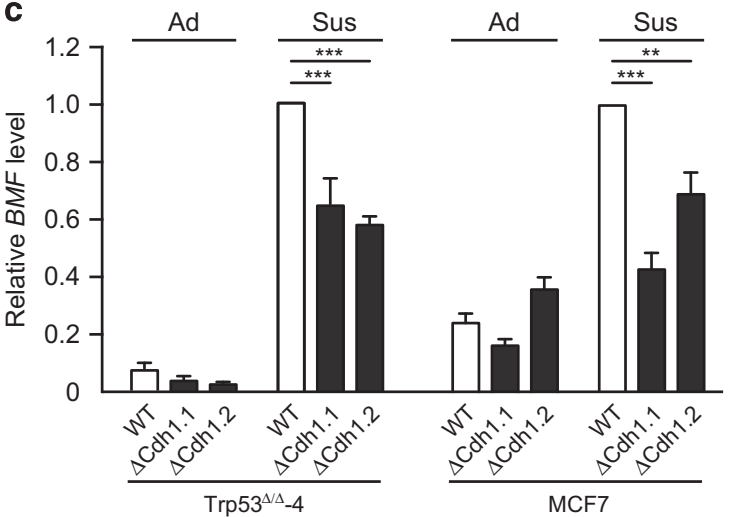

d

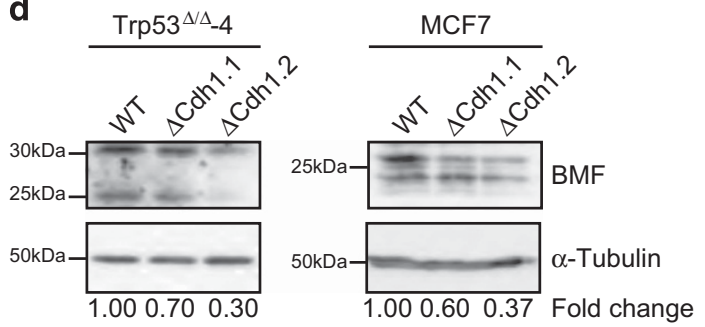

Figure 3 Loss of E-cadherin results in anoikis resistance and repression of BMF expression. (a) Immunofluorescence analysis of Trp53 $3^{\Delta / \Delta}$ and MCF7 cells targeted with E-cadherin-specific gRNA. $\triangle \mathrm{CDH1} 1$ and $\triangle \mathrm{CDH} 1.2$ cells grow dispersed, show loss of E-cadherin (Green) and cytoplasmic translocation of p120-catenin (Red) and fail to establish cell-cell junctions. (b) Acquisition of anoikis resistance upon loss of E-cadherin in Trp53 $3^{\Delta / \Delta}$ and MCF7 cells. Shown are quantifications of flow cytometry analyses of apoptosis and cell death using Annexin-V-FITC (fluorescein isothiocyanate) and propidium iodide after $24 \mathrm{~h}$ in $\mathrm{Ad}$ and Sus culture. Data represent mean \pm S.D., $n=3, t$-test ${ }^{*} P<0.05$, ${ }^{* \star} P<0.005$, ${ }^{* * *} P<0.0005$. (c) BMF is repressed in E-cadherin knockout Trp53 ${ }^{\Delta / \Delta}$ and MCF7 cells. Quantitative PCR analysis shows Bmf or BMF expression after $24 \mathrm{~h}$ in Ad and Sus culture conditions. Data are relative to mRNA levels in Sus cells. Data represent the mean \pm S.D., $n=3, t$ test ${ }^{* \star} P<0.005$, ${ }^{* \star *} P<0.0005$. (d) Western blotting analysis shows increased BMF protein expression in Trp53 ${ }^{\Delta / \Delta}$ and MCF7 cells cultured in Sus. Blots are cropped corresponding to the black box

suggesting that anchorage-independent E-cadherin-deficient breast cancer cells have a lower threshold for the BH3-only protein-dependent execution of anoikis. Together, these results show that increased levels of BMF or inhibition of BCL2 using the BMF-mimetic ABT-199 is sufficient to induce apoptosis in E-cadherin-negative cells, especially in an anchorage-independent setting.

As anoikis resistance is an excellent prognosticator of E-cadherin-negative breast cancer growth and metastasis, ${ }^{20,23}$ we investigated the effect of BMF expression on tumour growth in vivo. To this end, we orthotopically transplanted 10,000 mILC1 cells carrying either an empty vector or the iBMF expression vector in recipient mice and monitored tumour growth. Once tumours reached an average volume of $100 \mathrm{~mm}^{3}$, we induced BMF expression by feeding mice Dox-containing chow. Treatment of mILC1 cells carrying the empty expression vector with Dox either at a $100 \mathrm{~mm}^{3}$ or when metastasis was detected using bioluminescence imaging (BLI) did not result in significant changes in tumour growth
(Figure 7a). In contrast, BMF expression induced a significant reduction in tumour growth (Figure $7 \mathrm{~b}$ ). Moreover, induction of BMF expression when metastases were detected led to a robust 19-fold decrease in primary tumour volume (Figure 7c). Importantly, we observed a reduction in metastasis formation based upon BMF expression on thoracic BLI in Dox-fed mice when compared with control mice (Figures $7 d-h$ ).

In closing, our data establish that restriction of FOXO3dependent BMF expression underpins anchorageindependent tumour growth and metastasis of E-cadherinnegative breast cancer cells.

\section{Discussion}

Acquisition of anchorage independence through evasion of apoptosis is a hallmark of cancer. ${ }^{30}$ Metastatic cells have shifted the regulation of pro-apoptotic and anti-apoptotic mechanisms toward survival and have thereby gained the possibility to bypass the induction of anoikis during dissemination. 

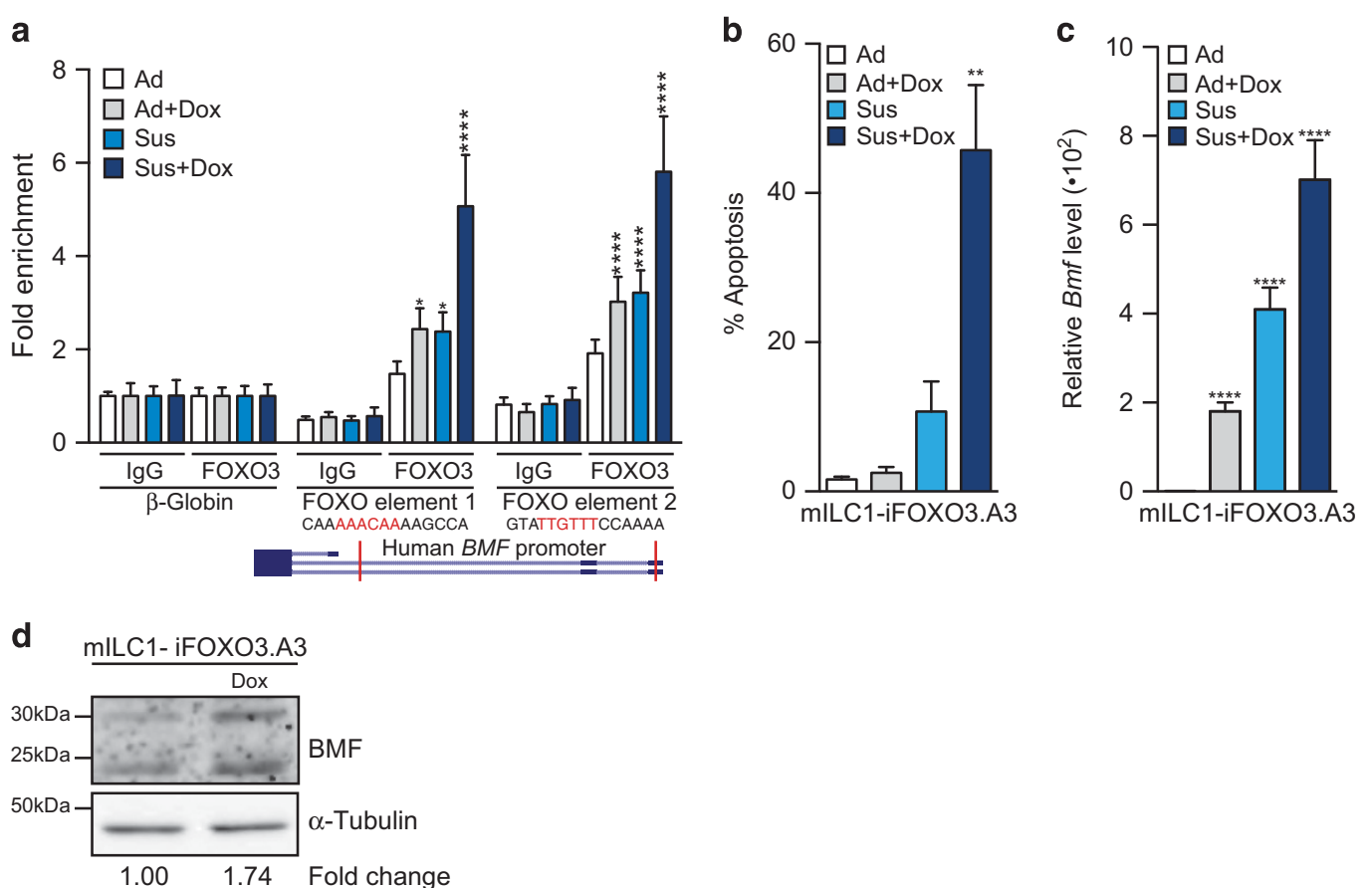

Figure 4 BMF is a direct FOXO3 target gene in breast cancer cells. (a) BMF is a direct FOXO3 target. FOXO3 binds the BMF promoter after AKT inhibition and during anchorage-independent growth. Average enrichment in BMF promoter chromatin recovery after FOXO3-ChIP in MCF7 growing under Ad, Sus and upon FOXO3 expression in Ad and Sus conditions (Ad+Dox, Sus+Dox, respectively). Data represent mean \pm S.D., $t$-test $n=3,{ }^{*} P<0.05,{ }^{* \star *} P<0.00005$. (b) Activation of FOXO induces anoikis. Quantification of anoikis in mILC1-iFOXO3.A3 measured by flow cytometry, data represent mean \pm S.D., $n=3, t$-test ${ }^{* *} P<0.005$. (c and d) FOXO3 activation induces BMF expression in mILC1. Shown are relative mRNA and protein levels in Sus upon FOXO3.A3 expression in mILC1 cells. Blots are cropped corresponding to the black box
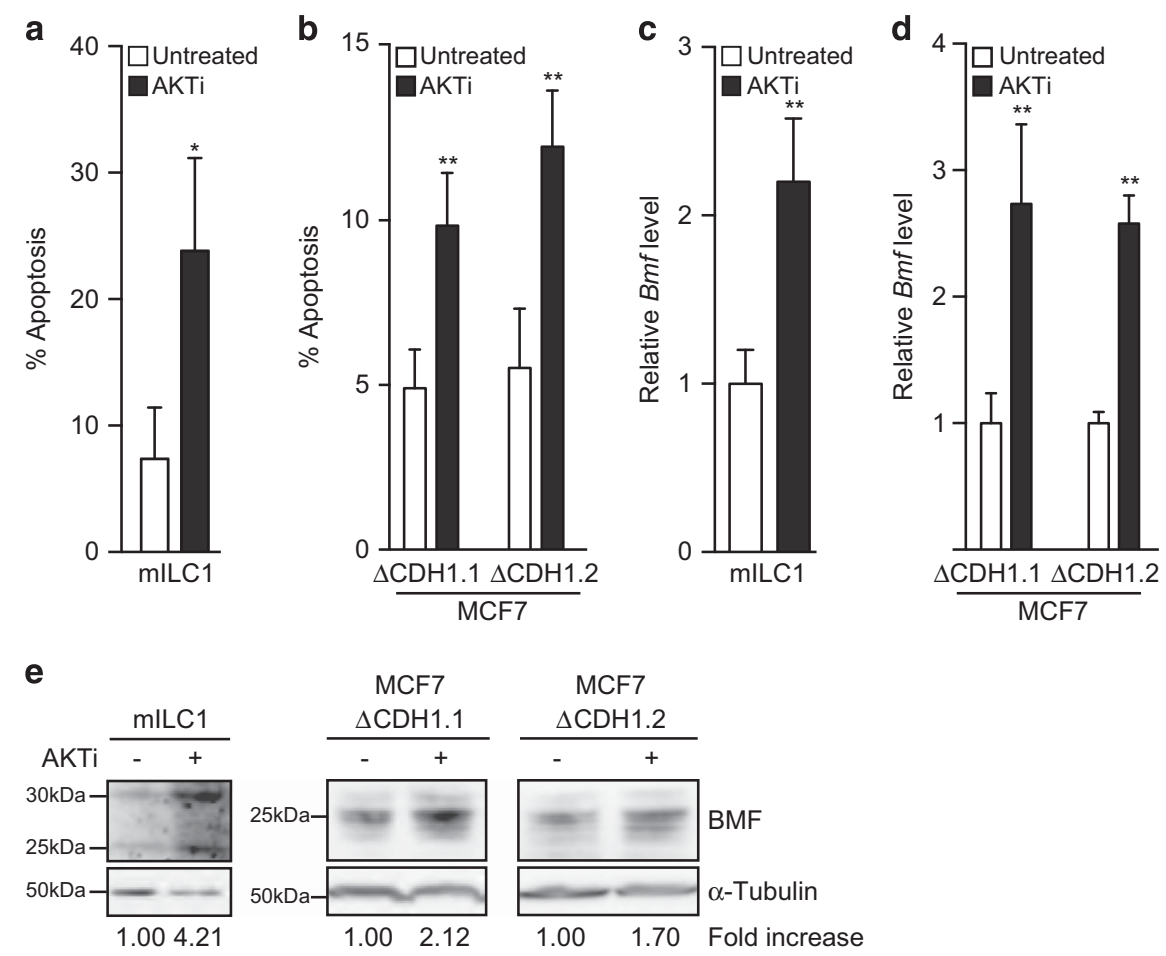

Figure 5 GFR signals restrain BMF expression through PI3K/AKT-dependent signals. (a and $\mathbf{b}$ ) Anoikis resistance in E-cadherin-negative breast cancer cells is AKT dependent. Shown is the quantification of anoikis induction in mILC1, MCF7- $\triangle$ CDH1.1 and MCF7- $\triangle$ CDH1.2 grown in Sus measured by flow cytometry. Data represent the mean \pm S.D., $n=3$, $t$-test ${ }^{\star} P<0.05,{ }^{* *} P<0.005$. (c-e) AKT inhibition results in BMF expression. Shown are quantitative PCR analyses of Bmf/BMF mRNA and western blotting analyses of Bmf/BMF protein levels in mILC1, MCF7- $\triangle$ CDH1.1 and MCF7- $\triangle$ CDH1.2 cultured in Sus and after treatment with AKTi. Data represent the mean \pm S.D., $n=3, t$-test ${ }^{\star} P<0.05,{ }^{* *} P<0.005$. Blots are cropped corresponding to the black box 
a

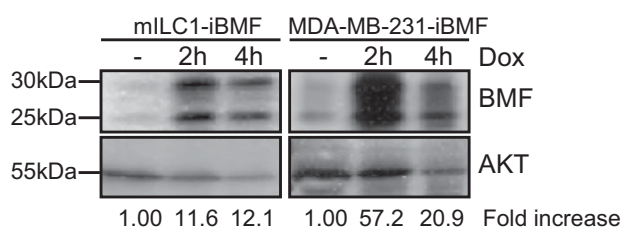

b

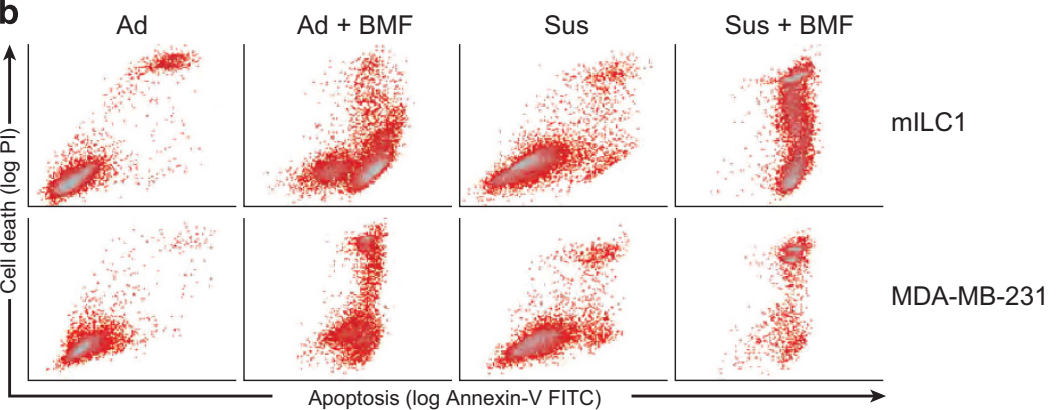

C

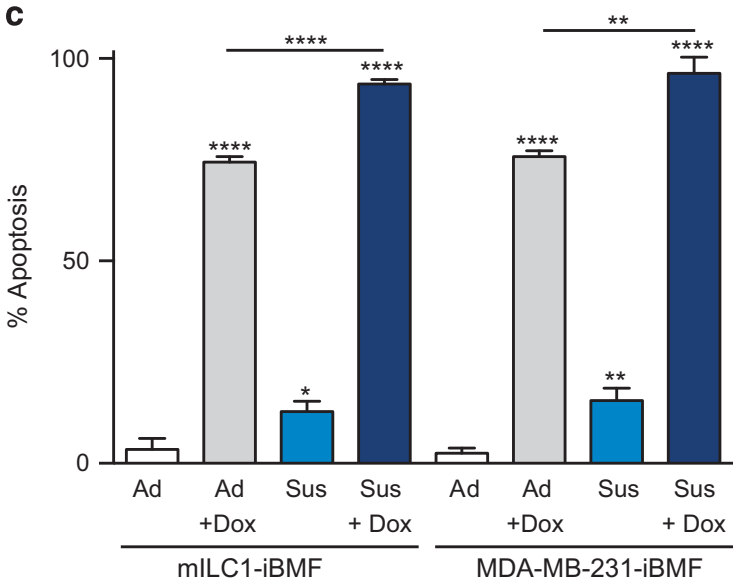

d

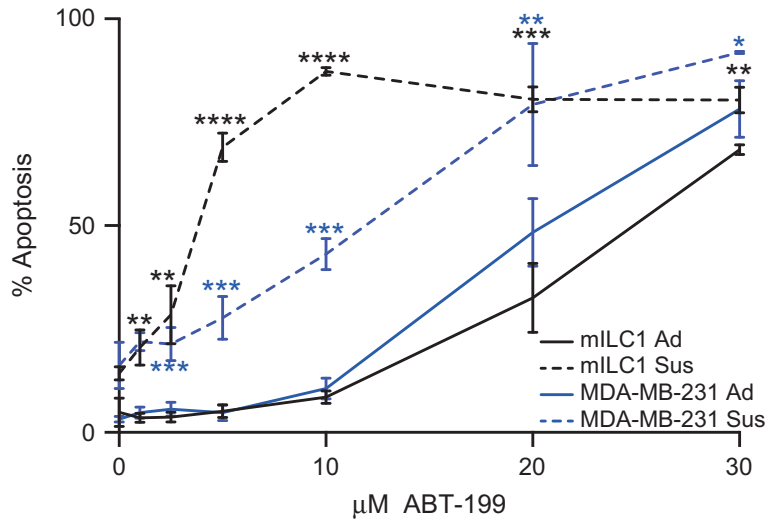

Figure 6 BMF expression is sufficient to induce apoptosis in E-cadherin-negative breast cancer cells. (a) Inducible expression of BMF in mILC1-iBMF and MDA-MB-231iBMF before and after Dox treatment. Blots are cropped corresponding to the black box. (b and $\mathbf{c}$ ) BMF expression induces apoptosis in mILC1 and MDA-MB-231 cells. Flow cytometric analysis of anoikis induction by Annexin-V-FITC (fluorescein isothiocyanate) and propidium iodide staining of mILC1-iBMF and MDA-MB-231-iBMF cells (b). (c) Depicts a quantification of the anoikis induction of mILC1-iBMF and MDA-MB-231-iBMF measured in panel (b). Data represent mean $\pm S$.D., $n=3, t$-test ${ }^{*} P<0.05,{ }^{* *} P<0.005$, ${ }^{* * *} P<0.0005$, ${ }^{* * \star *} P<0.00005$. (d) Induction of apoptosis and anoikis by the BMF mimetic ABT-199. FACS analysis of apoptosis induction using Annexin-V-FITC and propidium iodide staining of mILC1 and MDA-MB-231 cells after $24 \mathrm{~h}$ of treatment with ABT-199 in Ad and Sus conditions. Data represent mean \pm S.D., $n=3,{ }^{*} P<0.05,{ }^{* *} P<0.005$, ${ }^{\star * \star} P<0.0005,{ }^{* \star \star \star} P<0.00005$

Activation of growth factor signalling in cancer cells is essential for anoikis resistance owing to modulation of expression and activity of apoptotic factors. ${ }^{25}$ Others and we have demonstrated that inactivation of E-cadherin underpins anoikis resistance in breast cancer cells, a finding that appears to depend on hyper-sensitisation of GFR signalling through AKT/PKB and ERK upon dismantling of the AJ complex. ${ }^{17,18,20,23,31}$ As these mechanisms confer constitutive activation of GFR signals in breast cancer cells, it provides a clear rationale for the maintenance of anoikis resistance in E-cadherin-deficient breast cancer cells. Although AKT/PKB and ERK can control the posttranslational modulation of BAD, $\mathrm{BIM}$ and BAX, our current data show that anoikis-resistant breast cancer cells restrain BMF transcription, the main proapoptotic factor uniformly expressed in E-cadherin-expressing breast cancer cells upon transfer to anchorage independence. ${ }^{15,16,32}$ Elegant studies by the Brugge laboratory have identified BIM and BMF as key anoikis regulators of luminal mammary cells, a process counterbalanced by constitutive activation of growth factor-induced PI3K/AKT pathways. ${ }^{5,6}$ However, the underlying mechanism that prevented metastatic breast cancer cells from expressing BMF upon loss of anchorage remained unclear. As we detected clear changes in BMFmRNA levels upon transfer to anchorage independence when comparing breast cancer cells in the context of E-cadherin expression, we probed for transcriptional upstream cues, which resulted in our finding that FOXOs are key players in the regulation of $B M F$ expression in breast cancer.

BMF can directly compete for BAK/BAX binding with BCL2 and thereby drive apoptosis. Our data indicate that the increase in BMF expression, rather than the levels of BLC2, is the rate-limiting factor driving breast cancer cell survival. First, the robust upregulation in BMF mRNA expression in anoikis-sensitive cells combined with reduced BMF expression in anoikis-resistant cells led us to think that a specific BMF threshold should be reached to induce anoikis. Second, although anoikis-resistant cells induced BMF transcription in the absence of anchorage, this did not trigger anoikis, despite expressing comparable levels of BCL2 when compared with anoikis-sensitive cells. In line with this, we did not detect differences in the expression levels of BCL2 upon transfer to anchorage independence between cell lines. Finally, we could force anoikis-resistant cells to undergo apoptosis by ectopic expression of BMF or treatment with ABT-199. Together, our data show that loss of the AJ leads to GFR-induced signals that block FOXO-dependent BMF expression, a feature that is essential for survival in breast cancer cells during metastasis. 


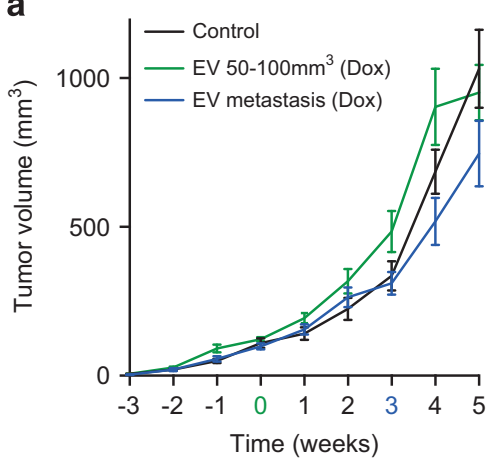

b
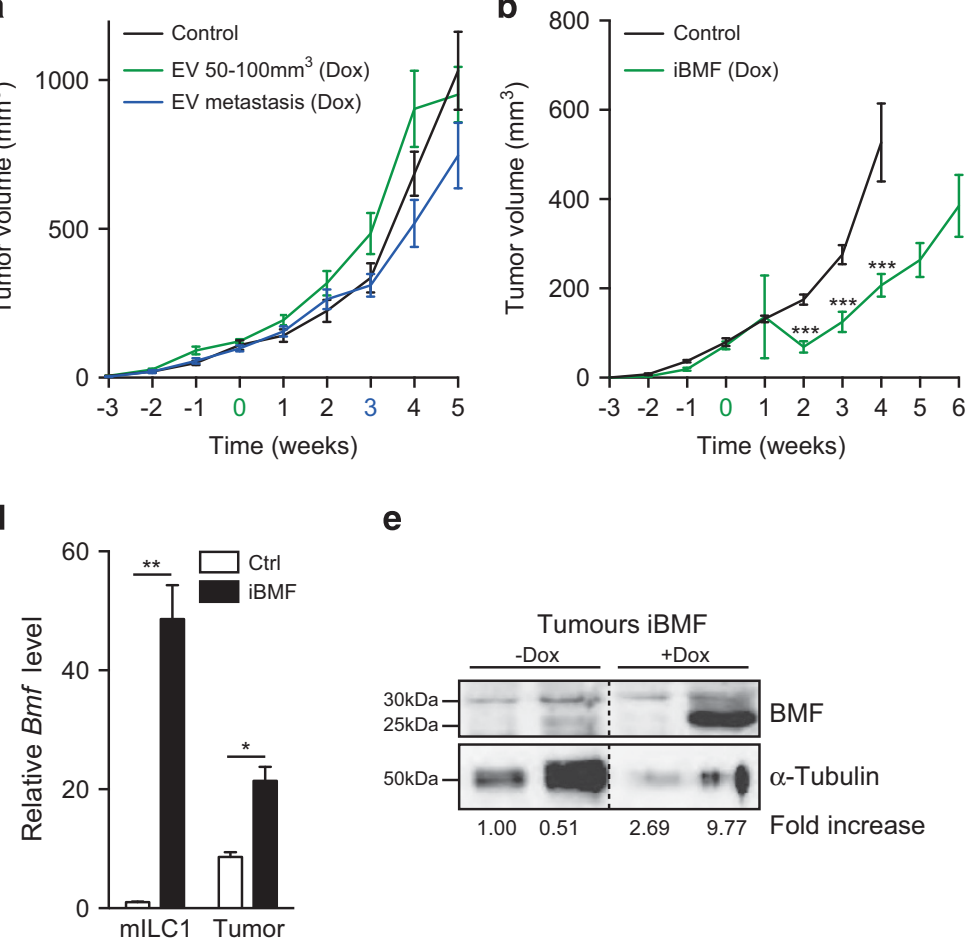

e

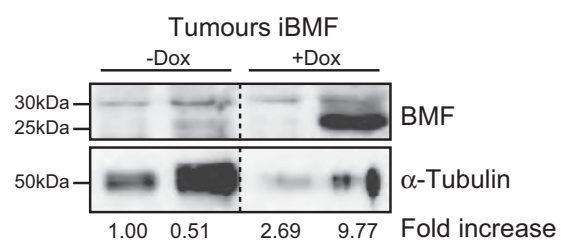

C

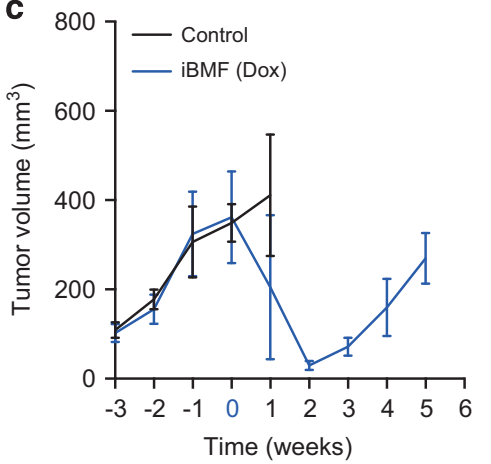

f Metastasis free tumor progression

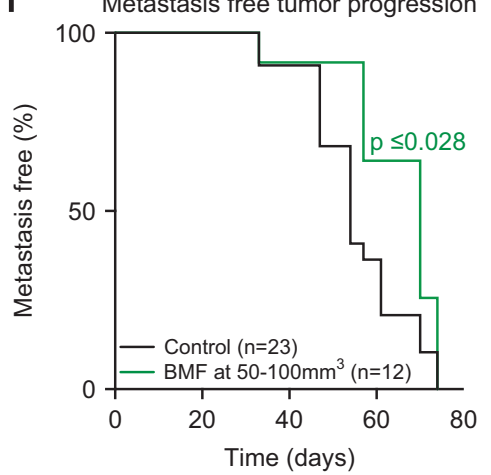

g

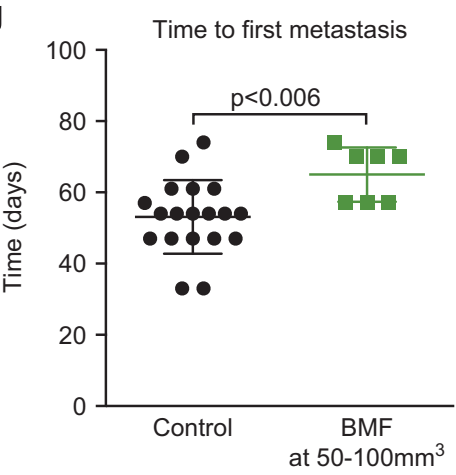

h

\begin{tabular}{|c|c|c|c|}
\cline { 2 - 4 } \multicolumn{1}{c|}{} & $\mathrm{n}$ & Metastasis & $\begin{array}{c}\text { days untill } \\
\text { metastasis }\end{array}$ \\
\hline control & 23 & 19 & $53.11 \pm 10.34$ \\
\hline BMF induction at $50-100 \mathrm{~mm}^{3}$ & 12 & 7 & $65.00 \pm 7.61$ \\
\hline
\end{tabular}

Figure 7 BMF expression restrains anchorage-independent tumour growth and metastasis of E-cadherin-negative breast cancer cells. (a) Dox treatment does not influence tumour growth of mILC1 cells carrying the empty Dox-inducible expression vector (EV). (b) BMF expression inhibits mammary tumour growth in mice. Primary tumour growth of control mice $(n=10)$ and mice treated with Dox $(n=12)$, which was started when tumours reached a volume of $100 \mathrm{~mm}^{3}$. Data represent the mean tumour volume \pm S.E.M., Holm-Sidak corrected $t$-test ${ }^{* * *} P<0.0005$. (c) BMF expression inhibits mammary tumour growth in mice with metastatic disease. Primary tumour growth of control $(n=10)$ and mice treated with Dox ( $n=13$ ), which was started when lung metastasis were detected by BLI ( $>2 \times 10^{3}$ photons $/ \mathrm{s} / \mathrm{cm}^{2} / \mathrm{sr}$ ), data represent the mean tumour volume \pm S.E.M. (d) Successful BMF expression after Dox treatment was determined by quantitative PCR analysis of the parental mILC1-iBMF and in primary tumours derived from either untreated or Dox-treated mice. Data represent mean \pm S.D., $n=3$, t-test ${ }^{\star} P<0.05, P<0.005$. (e) Western blotting analysis of tumour lysates shows Bmf induction upon Dox treatment of mice. Two untreated (- Dox) and treated (+Dox) tumours are shown, respectively. (f) BMF expression inhibits metastasis formation of mILC1 cells. Kaplan-Meier curve representing metastasis-free tumour progression measured in days until metastasis were detected by BLI in control mice $(n=23)$ and mice treated with Dox at a primary tumour volume of 50 $100 \mathrm{~mm}^{3}(n=12)$, Mantel-Cox test $P=0.028$. ( $\mathbf{g}$ and $\left.\mathbf{h}\right)$ Time until first metastasis are detected by BLI in control mice $(n=19)$ and mice treated with Dox at a primary tumour volume of $50-100 \mathrm{~mm}^{3}(n=7)$. Data represent individual mice with detected metastasis $\left(>2 \times 10^{3}\right.$ photons $\left./ \mathrm{s} / \mathrm{cm}^{2} / \mathrm{sr}\right) \pm$ S.D., Welch's corrected $t$-test $P<0.0062$

Our results indicate that FOXO-dependent transcription of $B M F$ may be subject of epigenetic regulation as well. Although we have ectopically activated $\mathrm{FOXO} 3$ under anchoragedependent and -independent conditions, we detected further enhanced $\mathrm{FOXO} 3$ binding at the BMFpromoter in suspension. The chromatin state of the BMF locus is expected to influence FOXO3 binding, as it is known that $\mathrm{FOXO}$ prefers to bind genomic regions associated with activating epigenetic marks. ${ }^{33,34}$ Histone deacetylase (HDAC) activity has been reported as a negative regulator of $B M F$ expression, because inhibition of HDACs results in BMF expression in multiple human cancer cell lines. ${ }^{35,36}$ How BMF is regulated posttranscriptionally remains to be fully characterised, but it was previously described that phosphorylation of ERK2 can inactivate BMF function. ${ }^{37,38}$ In line with these findings, complementing HDAC inhibition with inhibitors of mitogenic signalling, that is, B-RAF, augments the pro-apoptotic effect of BMF. $^{39}$ This might also explain why BMF induction does not 
directly lead to apoptosis in anchorage-independent MDAMB-231 cells that show a constitutively elevated growth factor signalling owing to oncogenic KRAS and B-RAF mutations. ${ }^{40}$

Loss of BMF has been linked to tumour suppression in several cancer types. ${ }^{41}$ Preclinical intervention strategies using $\mathrm{BH} 3$-only mimetics as monotherapy have been successful but mostly in lymphoid malignancies. ${ }^{42,43}$ Recent studies indicated that BH3-mimetics can be used to treat nonlymphoid cancers but mostly in combination with oestrogen antagonists, proteasome inhibitors, specific PI3K-mTOR inhibitors or chemotherapy. ${ }^{24,44-49}$ As previous findings from our laboratory demonstrated that E-cadherin-negative lobular breast cancer depends on p120-catenin-mediated activation of RhoA, Rock and subsequent actomyosin contraction, ${ }^{26}$ we anticipate that dual inhibition of these pathways might be successful in E-cadherin-negative cancers that are not driven by oncogenic activation of GFR pathways. Although we do not yet know whether RhoA-Rock signals converge onto the GFR-AKT-FOXO axis in the regulation of anoikis resistance, the fact that FOXO expression had no effect on survival of B-RAF/KRAS-mutated MDA-MB-231 cells seems to be in line with this assumption. Moreover, given that human invasive lobular carcinoma mostly expresses ER and responds to oestrogen antagonists, our findings provide an additional option to improve current treatment regimens in lobular breast cancer by using a combination BH3-mimetics and ERtargeted drugs.

In conclusion, we have linked activation of GFR pathways to inhibition of FOXO3-dependent BMF expression and the regulation of anchorage-independent tumour growth and metastasis in E-cadherin-negative metastatic breast cancer cells.

\section{Materials and Methods}

Cell lines. Mouse breast cancer cell lines $\operatorname{Trp} 53^{\Delta / \Delta}-4$ (KP8) and mILC1 (KEP1) were derived from tumours that developed in female $\mathrm{K} 14 \mathrm{cre}$; $\mathrm{Trp} 53^{\mathrm{F} / \mathrm{F}}$ and $\mathrm{K} 14 \mathrm{cre}$; $\mathrm{Cdh}^{\mathrm{F} / \mathrm{F}} ; \mathrm{Trp} 53^{\mathrm{F} / \mathrm{F}}$ mice and cultured as described previously. ${ }^{23}$ Human breast cancer cell lines MCF7 and MB-MDA-231 were verified by STR analysis and cultured as described. ${ }^{18}$

Constructs, lentiviral transduction and transfections. Lentiviral cDNA expression vectors expressing iBMF, iFOXO3 and iFOXO3.A3 were generated using Gateway cloning in the pINDUCER20 Dox-inducible expression system. ${ }^{50}$ Guide RNAs for Cdh1.1 and Cdh1.2 CRISPR were cloned into the lentiviral pSicoR CRISPR/Cas9 vector ${ }^{51}$ using $B s m B \mid$ restriction sites (Supplementary Table S1). After lentiviral transduction, cells were selected for incorporation using puromycin and subsequently FACS-sorted based on E-cadherin expression (DECMA-1, 1 : 2000; Abcam no. 11512, Cambridge, UK). BMF and BIM knockdown in Trp53 ${ }^{\Delta / \Delta}-4$ cells was achieved by lentiviral transduction of pLKO1shBMF (TRCN0000009716 (shBMF \#1) and TRCN0000009717 (shBMF \#2)) and pLKO1-shBIM (TRCN0000231244 (shBIM \#1) and TRCN0000231246 (shBIM \#2), Sigma-Aldrich, Zwijndrecht, The Netherlands), followed by puromycin selection. For MCF7, siRNA smartpools targeting BMF, BIM or control siRNA (Dharmacon M-004393-04-0005 and M-004383-02-0005, Lafayette, CO, USA) were reversetransfected using HiPerfect (Qiagen, Venlo, The Netherlands) at a final siRNA concentration of $40 \mathrm{nM}$. Forty-eight hours after transfection, cells were harvested and seeded for anoikis assays. ${ }^{50,51}$

Immunoblotting and antibodies. Proteins were detected using SDS-PAGE and subsequent western blotting analysis with primary antibodies recognising BAD (CST-9292, Cell Signaling Technology, Leiden, The Netherlands), BIM (CST-2819) BMF (human: CST-5889, mouse: ENZO-17A9), BID (SC-11423 Santa Cruz, Heidelberg, Germany), AKT/PKB (CST), FOXO1 (CST- 29H4), FOXO3 (H144 Santa Cruz), NOXA (SP7122p Acris, Herford, Germany), PUMA (CST-4976) and BCL2 (CST-2876) used at $1: 2000$. Primary antibodies were detected by secondary
HRP-conjugated antibodies targeting mouse, rabbit and rat IgG and visualised using chemiluminescence (Bio-Rad, Veenendaal, The Netherlands).

Immunofluorescence. Cells were grown on glass coverslips, fixed using icecold methanol and blocked with 2\% BSA (Invitrogen, Breda, The Netherlands) and $0.1 \%$ normal goat serum (Invitrogen). Cells were stained with mouse anti-p120 (BD616134, 1: 500 overnight), Alexa Fluor 555-conjugated mouse anti-E-cadherin, ( $1: 200, B D 560064,2 \mathrm{~h}$ at room temperature) and DAPI (Sigma-Aldrich). Secondary 563-conjugated goat anti-mouse antibodies were used for visualisation on a Zeiss LSM700 confocal microscope (Sliedrecht, The Netherlands).

Quantitative real-time PCR. mRNA was isolated from live cells using the Qiagen RNeasy Kit (Qiagen). cDNA synthesis was performed using the iScript cDNA Synthesis Kit (Bio-Rad). Real-time PCR was performed using SYBR green FastStart master mix (Roche, Woerden, The Netherlands) in the CFX Connect Real-time PCR detection system (Bio-Rad). Target genes were amplified using the specific primer pairs (Supplementary Table S1), and specificity was confirmed by analysis of the melting curves. Target gene expression levels were normalised to GAPDH, PBDG and TUBA1A levels.

Anoikis assays. Anoikis resistance was analysed by seeding six-well ultra-low cluster polystyrene culture dishes (Corning, Corning, NY, USA) with $50000 \mathrm{cell} / \mathrm{s} / \mathrm{ml}$. After $24 \mathrm{~h}$, cells were harvested and resuspended in $100 \mathrm{ml}$ of Annexin-V buffer supplemented with Annexin-V (IQ Products, Groningen, The Netherlands) and propidium iodide (Sigma-Aldrich). Anoikis was defined as the Annexin-V and propidium iodide-positive population and quantified using a FACSCalibur (BD Biosciences, Breda, The Netherlands).

Chromatin immunoprecipitation. MCF7-iFOXO3 cells were grown under adherent (Ad) or suspension (Sus) conditions in the absence or presence of Dox and treated with the allosteric AKT inhibitor VIII $1 \mathrm{~h}$ prior to harvesting to ensure full FOXO activation. Immunoprecipitations were performed on $20 \times 10^{6}$ cells with $5 \mu \mathrm{g}$ rabbit anti-FOXO3 (Santa Cruz H144) and $5 \mu \mathrm{g}$ of normal rabbit IgG (Santa Cruz). ChIPs were performed as previously described. ${ }^{52}$

Orthotopic transplantations and tumour watch. For longitudinal tumour growth and dissemination experiments, $10000 \mathrm{mlLC} 1$ cells were transplanted in the fourth inguinal mouse mammary gland of Nude-recipient mice as described previously. ${ }^{26}$ Primary tumours were allowed to develop to a volume of $100 \mathrm{~mm}^{3}$ at which point expression of BMF was induced by feeding Dox-containing chow (Ssniff, Soest, Germany). Alternatively, BMF expression was induced when lung metastasis were detected using BLI of the thorax $\left(>2 \times 10^{3}\right.$ photons $\left./ \mathrm{s} / \mathrm{cm}^{2} / \mathrm{sr}\right)$. Tumour volumes and lung metastases were followed in time as described using a Biospace $\phi$ imager (Nesles la Vallée, France). ${ }^{26}$ All animal experiments were approved by the Utrecht University Animal Experimental Committee (DEC-ABC no. 2012.III.05.044).

\section{Conflict of Interest}

The authors declare no conflict of interest.

Acknowledgements. We thank S Elledge from the HHMl Boston and R Lebbink of the Molecular Microbiology Department, UMC, Utrecht for kindly providing the pINDUCER20 and pSicoR CRISPR/Cas9 constructs and the UMC Utrecht Cell Biology Department for help with confocal imaging. The Derksen, van Diest, Dansen and Burgering laboratories are acknowledged for support and suggestions. Research was supported by grants from the Netherlands Organization for Scientific Research (NWO/ZonMW-VIDI 016.096.318), Foundation Vrienden UMC Utrecht (11.081) and the Dutch Cancer Society (KWF-UU-2011-5230 and KWF-UU-2009-4490).

1. Frisch SM, Screaton RA. Anoikis mechanisms. Curr Opin Cell Biol 2001; 13: 555-562.

2. Schwartz MA. Integrins, oncogenes, and anchorage independence. J Cell Biol 1997; 139: 575-578.

3. Humphreys RC, Krajewska M, Krnacik S, Jaeger R, Weiher H, Krajewski S et al. Apoptosis in the terminal endbud of the murine mammary gland: a mechanism of ductal morphogenesis. Development 1996; 122: 4013-4022. 
4. Debnath J, Mills KR, Collins NL, Reginato MJ, Muthuswamy SK, Brugge JS. The role of apoptosis in creating and maintaining luminal space within normal and oncogene-expressing mammary acini. Cell 2002; 111: 29-40.

5. Schmelzle T, Mailleux AA, Overholtzer M, Carroll JS, Solimini NL, Lightcap ES et al. Functional role and oncogene-regulated expression of the BH3-only factor Bmf in mammary epithelial anoikis and morphogenesis. Proc Natl Acad Sci USA. 2007; 104: 3787-3792.

6. Mailleux AA, Overholtzer M, Schmelzle T, Bouillet P, Strasser A, Brugge JS. BIM regulates apoptosis during mammary ductal morphogenesis, and its absence reveals alternative cell death mechanisms. Dev Cell 2007; 12: 221-234.

7. Westphal D, Dewson G, Czabotar PE, Kluck RM. Molecular biology of Bax and Bak activation and action. Biochim Biophys Acta 2011; 1813: 521-531.

8. Strasser A, Cory S, Adams JM. Deciphering the rules of programmed cell death to improve therapy of cancer and other diseases. EMBO J 2011; 30: 3667-3683.

9. Hausmann M, Leucht K, Ploner C, Kiessling S, Villunger A, Becker $\mathrm{H}$ et al. BCL-2 modifying factor (BMF) is a central regulator of anoikis in human intestinal epithelial cells. $J$ Biol Chem 2011; 286: 26533-26540.

10. Puthalakath H, Villunger A, O'Reilly LA, Beaumont JG, Coultas L, Cheney RE et al. Bmf: a proapoptotic $\mathrm{BH}$-only protein regulated by interaction with the myosin $\mathrm{V}$ actin motor complex, activated by anoikis. Science 2001; 293: 1829-1832.

11. Chiarugi $P$, Giannoni E. Anoikis: a necessary death program for anchorage-dependent cells. Biochem Pharmacol 2008; 76: 1352-1364.

12. Muthuswamy SK, Li D, Lelievre S, Bissell MJ, Brugge JS. ErbB2, but not ErbB1, reinitiates proliferation and induces luminal repopulation in epithelial acini. Nat Cell Biol 2001; 3: 785-792.

13. Danes CG, Wyszomierski SL, Lu J, Neal CL, Yang W, Yu D. 14-3-3 zeta down-regulates p53 in mammary epithelial cells and confers luminal filling. Cancer Res 2008; 68: 1760-1767.

14. Samuels Y, Wang Z, Bardelli A, Silliman N, Ptak J, Szabo S et al. High frequency of mutations of the PIK3CA gene in human cancers. Science 2004; 304: 554.

15. Datta SR, Dudek H, Tao X, Masters S, Fu H, Gotoh Y et al. Akt phosphorylation of BAD couples survival signals to the cell-intrinsic death machinery. Cell 1997; 91: 231-241.

16. Gardai SJ, Hildeman DA, Frankel SK, Whitlock BB, Frasch SC, Borregaard N et al. Phosphorylation of Bax Ser184 by Akt regulates its activity and apoptosis in neutrophils. J Biol Chem 2004; 279: 21085-21095.

17. Qian X, Karpova T, Sheppard AM, McNally J, Lowy DR. E-cadherin-mediated adhesion inhibits ligand-dependent activation of diverse receptor tyrosine kinases. EMBO J 2004; 23: 1739-1748.

18. Schackmann RCJ, Klarenbeek S, Vlug EJ, Stelloo S, van Amersfoort M, Tenhagen M et al. Loss of p120-catenin induces metastatic progression of breast cancer by inducing anoikis resistance and augmenting growth factor receptor signaling. Cancer Res 2013; 73: 4937-4949.

19. van Roy F, Berx G. The cell-cell adhesion molecule E-cadherin. Cell Mol Life Sci 2008; 65 3756-3788.

20. Derksen PWB, Braumuller TM, van der Burg E, Hornsveld M, Mesman E, Wesseling J et al. Mammary-specific inactivation of E-cadherin and p53 impairs functional gland development and leads to pleomorphic invasive lobular carcinoma in mice. Dis Models Mech 2011; 4: 347-358.

21. Boussadia O, Kutsch S, Hierholzer A, Delmas V, Kemler R. E-cadherin is a survival factor for the lactating mouse mammary gland. Mech Dev 2002; 115: 53-62.

22. Berx G, van Roy F. Involvement of members of the cadherin superfamily in cancer. Cold Spring Harb Perspect Biol 2009; 1: a003129.

23. Derksen PWB, Liu X, Saridin F, van der Gulden H, Zevenhoven J, Evers B et al. Somatic inactivation of E-cadherin and p53 in mice leads to metastatic lobular mammary carcinoma through induction of anoikis resistance and angiogenesis. Cancer Cell 2006; 10: 437-449.

24. Vaillant F, Merino D, Lee L, Breslin K, Pal B, Ritchie ME et al. Targeting BCL-2 with the BH3 mimetic ABT-199 in estrogen receptor-positive breast cancer. Cancer Cell 2013; 24: 120-129.

25. Muranen T, Selfors LM, Worster DT, Iwanicki MP, Song L, Morales FC et al. Inhibition of $\mathrm{PI} 3 \mathrm{~K} / \mathrm{mTOR}$ leads to adaptive resistance in matrix-attached cancer cells. Cancer Cell 2012 21: 227-239.

26. Schackmann RCJ, van Amersfoort M, Haarhuis JHI, Vlug EJ, Halim VA, Roodhart JML et al. Cytosolic p120-catenin regulates growth of metastatic lobular carcinoma through Rock1mediated anoikis resistance. J Clin Invest 2011; 121: 3176-3188.

27. Reginato MJ, Mills KR, Becker EB, Lynch DK, Bonni A, Muthuswamy SK et al. Bim regulation of lumen formation in cultured mammary epithelial acini is targeted by oncogenes. Mol Cell Biol 2005; 25: 4591-4601.
28. Eijkelenboom A, Burgering BMT. FOXOs: signalling integrators for homeostasis maintenance. Nat Rev Mol Cell Biol 2013; 14: 83-97.

29. Brunet A, Bonni A, Zigmond MJ, Lin MZ, Juo P, Hu LS et al. Akt promotes cell survival by phosphorylating and inhibiting a Forkhead transcription factor. Cell 1999; 96: 857-868.

30. Hanahan D, Weinberg RA. Hallmarks of cancer: the next generation. Cell 2011; 144: 646-674.

31. Curto M, Cole BK, Lallemand D, Liu CH, McClatchey Al. Contact-dependent inhibition of EGFR signaling by Nf2/Merlin. J Cell Biol 2007; 177: 893-903.

32. Juin P, Geneste O, Gautier F, Depil S, Campone M. Decoding and unlocking the BCL-2 dependency of cancer cells. Nat Rev Cancer 2013; 13: 455-465.

33. Eijkelenboom A, Mokry M, de Wit E, Smits LM, Polderman PE, van Triest MH et al. Genomewide analysis of $\mathrm{FOXO} 3$ mediated transcription regulation through RNA polymerase II profiling. Mol Syst Biol 2013; 9: 638.

34. Eijkelenboom A, Mokry M, Smits LM, Nieuwenhuis EE, Burgering BMT. FOXO3 selectively amplifies enhancer activity to establish target gene regulation. Cell Rep 2013; 5: 1664-1678.

35. Zhang Y, Adachi M, Kawamura R, Imai K. Bmf is a possible mediator in histone deacetylase inhibitors FK228 and CBHA-induced apoptosis. Cell Death Differ 2006; 13: 129-140.

36. Shao Y, Aplin AE. BH3-only protein silencing contributes to acquired resistance to PLX4720 in human melanoma. Cell Death Differ 2012; 19: 2029-2039.

37. VanBrocklin MW, Verhaegen M, Soengas MS, Holmen SL. Mitogen-activated protein kinase inhibition induces translocation of Bmf to promote apoptosis in melanoma. Cancer Res 2009; 69: 1985-1994.

38. Shao Y, Aplin AE. ERK2 phosphorylation of serine 77 regulates Bmf pro-apoptotic activity. Cell Death Dis 2012; 3: e253.

39. Bolden JE, Shi W, Jankowski K, Kan CY, Cluse L, Martin BP et al. HDAC inhibitors induce tumor-cell-selective pro-apoptotic transcriptional responses. Cell Death Dis 2013; 4: e519.

40. Chen J, Gomes AR, Monteiro LJ, Wong SY, Wu LH, Ng T-T et al. Constitutively nuclear FOXO3a localization predicts poor survival and promotes Akt phosphorylation in breast cancer. PLOS One 2010; 5: e12293.

41. Piñon JD, Labi V, Egle A, Villunger A. Bim and Bmf in tissue homeostasis and malignant disease. Oncogene 2008; 27 Suppl 1: S41-S52.

42. Labi V, Erlacher M, Kiessling S, Manzl C, Frenzel A, O'Reilly L et al. Loss of the BH3-only protein Bmf impairs $B$ cell homeostasis and accelerates gamma irradiation-induced thymic lymphoma development. J Exp Med 2008; 205: 641-655.

43. Chonghaile TN, Roderick JE, Glenfield C, Ryan J, Sallan SE, Silverman LB et al. Maturation stage of T-cell acute lymphoblastic leukemia determines BCL-2 versus BCL-XL dependence and sensitivity to ABT-199. Cancer Discov 2014; 4: 1074-1087.

44. Miller LA, Goldstein NB, Johannes WU, Walton CH, Fujita M, Norris DA et al. BH3 mimetic ABT-737 and a proteasome inhibitor synergistically kill melanomas through Noxa-dependent apoptosis. J Invest Dermatol 2009; 129: 964-971.

45. Choudhary GS, Al-Harbi S, Mazumder S, Hill BT, Smith MR, Bodo J et al. MCL-1 and $\mathrm{BCL}-\mathrm{XL}$-dependent resistance to the $\mathrm{BCL}-2$ inhibitor $\mathrm{ABT}-199$ can be overcome by preventing PI3K/AKT/mTOR activation in lymphoid malignancies. Cell Death Dis 2015; 6: e1593.

46. Reuland SN, Goldstein NB, Partyka KA, Cooper DA, Fujita M, Norris DA et al. The combination of $\mathrm{BH} 3$-mimetic $\mathrm{ABT}-737$ with the alkylating agent temozolomide induces strong synergistic killing of melanoma cells independent of p53. PLoS One 2011; 6: e24294.

47. Oakes SR, Vaillant F, Lim E, Lee L, Breslin K, Feleppa F et al. Sensitization of BCL-2expressing breast tumors to chemotherapy by the $\mathrm{BH} 3$ mimetic ABT-737. Proc Natl Acad Sci USA 2012; 109: 2766-2771.

48. Kutuk O, Letai A. Displacement of Bim by Bmf and Puma rather than increase in Bim level mediates paclitaxel-induced apoptosis in breast cancer cells. Cell Death Differ 2010; 17: $1624-1635$.

49. Mukherjee N, Reuland SN, Lu Y, Luo Y, Lambert K, Fujita M et al. Combining a BCL2 inhibitor with the retinoid derivative fenretinide targets melanoma cells including melanoma initiating cells. J Invest Dermatol 2015; 135: 842-850.

50. Meerbrey KL, Hu G, Kessler JD, Roarty K, Li MZ, Fang JE et al. The pINDUCER lentiviral toolkit for inducible RNA interference in vitro and in vivo. Proc Natl Acad Sci USA 2011; 108: 3665-3670.

51. van de Weijer ML, Bassik MC, Luteijn RD, Voorburg CM, Lohuis MA, Kremmer E et al. A high-coverage shRNA screen identifies TMEM129 as an E3 ligase involved in ER-associated protein degradation. Nat Commun 2014; 5: 3832

52. Renault VM, Thekkat PU, Hoang KL, White JL, Brady CA, Kenzelmann Broz D et al. The prolongevity gene $\mathrm{FoxO} 3$ is a direct target of the p53 tumor suppressor. Oncogene 2011; 30 : $3207-3221$. 